\title{
Dirigir el director. Historia de un documental sobre Fernando Birri
}

\author{
Dominique Dreyfus ${ }^{\bullet}$ \\ Université de Poitiers - Sorbonne
}

\section{El pedido}

En la primera década de los años 2000, el canal Cine-Cinéma de la televisión francesa, produjo una serie de documentales sobre el cine latino-americano para lo cual decidí hacer uno sobre Fernando Birri. Cuando le informé de la idea, me respondió: «Sobre mí, no. Pero sobre mi trabajo, mi carrera, mi visión del cine, eso sí.»

Este fue entonces el postulado sobre el cual elaboré mi proyecto de film.

Durante unos meses, entre 2008 y 2009, me dediqué al documental sobre Fernando Birri — sobre su trabajo, su carrera, su visión del cine. Fue la oportunidad de tejer con él una relación —efímera lo sé— de amistad, de complicidad, casi de intimidad. Una aproximación que él mismo fuera creando al firmar el primer mail que me escribió «Su Fer» indicando así — según mi interpretación—que se ponía a mi disposición con confianza y cariño. Así que hasta que el film estuviese listo, Fernando Birri seria mío...

Seria mío... y sin embargo, percibo diez años mas tarde que no sé, que nunca supe, nada de su vida privada. Excepto Carmen, su mujer, presencia silenciosa y amable durante todo el rodaje. Tal vez velase sobre «Su Fer», imparable seductor. Y si no, ¿que sé yo de Birri? ¿Tuvo otras mujeres? ¿Tenía hijos? ¿Hermanos? ¿Problemas de salud? ¿De dinero? ¿Afectivos? No lo sé. ¿Le gustaba el mar? ¿El monte? ¿El campo? No lo sé. ¿Sabía manejar? ¿Cocinar? ¿Jugar póker? No lo sé.

El trato fue claro: el documental era sobre su trabajo, su carrera, su visión del cine. De su vida privada, apenas lo que impactaba o explicaba su trabajo. O sea, cuestiones profesionales, únicamente profesionales. Por lo que cuando estuve en Roma donde vivía Birri, una primera vez para preparar el proyecto, y más tarde para rodar, nunca estuve en su casa. Los encuentros fueron siempre en su entorno de trabajo: «el estudio» o sea, un piso donde tenía su oficina de dibujo.

\footnotetext{
- Dominque Dreyfus (2010) Fernando Birri, argentin d'art et d'essai, L'Harmattan et les Films d'un Jour, Paris, Francia.

- Doctora en Literatura y Civilización Brasilera, enseñó en la Universidad de Poitiers, en la Sorbonne (Paris) y en la Escuela de Ciencias Políticas, en Francia. Es Periodista y trabajó en la prensa escrita (Liberation, Rolling Stone), la radio (Europe1, Radio latina) y la televisión (Canal +, France 2, M6). Autora de varios ensayos sobre Brasil y Portugal se dedica desde el final de los años '90 a la producción de documentales.
} 
Birri dibujaba — algo muy importante en su carrera - una salita no «de» lectura sino «con» lectura. Y a quien le apetecía un café, la cafetera del estudio no funcionaba, había que irse al barcito vecino: «Buongiorno, un caffè con latte per favore... Grazie tanto».

\section{Escribir}

Eterno viajante, Fernando Birri tuvo una vida de traslados, de idas y vueltas entre Santa Fe, Buenos Aires, Roma, Brasil, Cuba, México... entre libertad y represión, entre democracia y dictadura, entre trabajo y descanso. Vivía aquí, se exiliaba allá, iba a trabajar allí, se mudaba acá, y así era la existencia de nómade de Fernando Birri. Una vida en que se dibujaban espacios: países, ciudades, pisos, estudios...

Imaginé la sinopsis a partir de espacios: los espacios profesionales, los espacios de la carrera, los espacios del mundo cinematográfico de Fernando Birri. Teníamos que ir a Buenos Aires donde Birri empezó su formación de cineasta. Y a Santa Fe, no para conocer su ciudad natal, sino la ciudad donde fundó la primera escuela de cine de América Latina: el Instituto de Cinematografía de la Universidad Nacional del Litoral. Teníamos que ir a Brasil donde huyendo la dictadura militar en los años 60, se exilió algún tiempo, juntándose con cineastas brasileños como Nelson Pereira dos Santos y a Estados Unidos, donde se encuentra el archivo de Birri, en la Universidad de Brown. También a San Antonio de los Baños, en Cuba, para ver la Escuela de Cine y Televisión que Birri fundó y luego dirigió con Gabriel García Márquez. ¡Qué maravilloso imaginar esta pareja de genios! Pero por cuestiones de tiempo y plata nada de eso fue posible. Así que Fernando Birri no me haría visitar las escuelas de cine que había creado. Sin embargo, otra escuela de cine, tan importante cuanto las otras, me esperaba. La que lo había creado a él, el Centro Sperimentale di Cinematografía de Roma. Cerquita a la famosa Cinecittà estaba la escuela en que Fernando Birri completó su formación cinematográfica y firmó su personalidad.

Mi film se haría en el espacio de Roma, entre su estudio y el Centro Sperimentale. Dos espacios en que iríamos al encuentro de la vida profesional y artística de Birri. Espacios que, con el paso de las entrevistas y del vagar por los corredores, las salas, los jardines, evocarían los tiempos pasados y presentes, convocarían los recuerdos, los sueños, apelarían a la reflexión. Para cada tema su lugar específico. De espacio en espacio, desgranaríamos los pasos de la carrera de Fernando Birri. Una carrera movida por las circunstancias políticas, sociales, artísticas, profesionales.

A través de la palabra de Birri, mi propósito era buscar la historia del cine Argentino y mas aún, Latinoamericano que, como cineasta y teórico del cine, Birri revolucionó. Era también buscar la Historia, con una $\mathrm{H}$ grande, de la que Birri fue testigo y actor - y también víctima.

Pues su historia personal fue puntuada de exilios políticos, de huidas de persecución, de combates a dictaduras. Luchó con la misma convicción contra las que sufrió en Argentina como contra la que lo censuró en Cuba. Fernando Birri era políticamente intransigente y su cinematografía estaba en adecuación con sus ideas. Más que eso, su cinematografía era la aplicación práctica de sus ideas y también de su personalidad. Era un cine político, social, filosófico, existencial, poético, humorístico, fantasioso... 


\section{Rodar}

Todo eso, Birri lo contó con filosofía y poesía, con humor y fantasía durante los tres días en que rodamos. En función del tema de la entrevista, cambiábamos de escenario: el escritor en su salita con lectura. Dijo algunas palabritas sobre el tema y luego le gustó más leer un poema suyo dedicado a Don Quijote. El artista plástico en la oficina donde realizó un dibujo que me dedicó: lo tengo siempre encuadrado en mi sala de trabajo. Dibujaba y hablaba al mismo tiempo de su relación con la pintura y el dibujo, parte esencial de su trabajo de guionista. En la oficina, sentado frente a su computador, tratamos de política. No de LA política, sino de LO político. Pero también de la política, aquella que lo persiguió, que decidió del rumbo que tomó su vida.

Cambio de tema, cambio de espacio. Pasamos un día en el Centro Sperimentale di Cinematografia. En el día del rodaje, fuimos en taxi a buscarlo y al llegar al Centro, vi a Fernando Birri tan emocionado que me di cuenta que él no retornaba allí desde hacía mucho tiempo. Tuve el privilegio de verlo de repente con 20 años, llegando a Roma, descubriendo el neorrealismo italiano, viendo enfrente suyo, de verdad, a sus maestros De Sica, Rossellini, Zavattini... El personal del centro lo recibió como un héroe. Nos entregaron «la casa» por ese día (y nos invitaron al almuerzo en la cantina). Habíamos escogido un día sin clases para no perturbar la vida de la escuela ni ser tampoco perturbados por ella. Y más aún, para crear un clima onírico: Birri deambulando a través de la escuela vacía, como si estuviera soñando. Le encantó la idea y, como buen actor, jla actuó perfectamente!

$\mathrm{Si}$ en el espacio privado del estudio el tema fue la faceta «interna» de Birri - el trabajo consigo mismo, su proceso de creación, su relación con el cine, el arte, su compromiso ideológico, su visión del mundo... en el espacio público de la escuela, el tema fue su faceta externa: el trabajo con los otros, el aprendizaje, la transmisión, la creación, las influencias...

Sé que esos días de rodaje intensos y alegres no fueron más que tres. Pero en mi memoria tengo la sensación de que viví semanas, meses, al lado de Fernando Birri... La realidad es que fueron más de tres días: hubo los encuentros previos para preparar el proyecto, luego el rodaje y al final el montaje.

\section{Montar}

Al largo de las cinco semanas que siguieron, me comuniqué regularmente con Birri : «Fernando, en el fragmento de Che, Buenos Aires que quiero poner en el documental, quisiera cambiar la música y poner una notas del Sheherazade de Rimsy Korsakov. Puedo?» «Ah! claro, quedará muy hermoso, me encanta Rimsy Korsakov»; «Fernando, ¿no tendrías unas fotos tuyas con Gabriel García Márquez?» «Lo tengo todo en la Biblioteca de la Universidad de Brown — la única institución que se interesó por mi archivo. Argentina, Cuba, Italia... ninguno de estos países lo quisieron...», «Fernando necesito 
una copia Beta de tus películas, pero ni el mismísimo Museo del filme de Buenos Aires que me recomendaste los tiene...» «Estoy masterizando mis películas, pero es un trabajo monumental, aún no tengo nada listo que te pueda pasar.»

No tuve otra solución que utilizar las copias VHS de mi archivo. Muy poco profesional... Y sin embargo la calidad lamentable de la imágenes de las películas que figuran en el documental cuentan de la historia de Birri, de la historia del cine argentino, de la Historia de Argentina. Como lo explica Birri en el documental, la dictadura quemó todos los negativos de todas las películas de Nuevo cine argentino... películas subversivas, como todo lo que vino de Birri, jel hombre que abrió el camino del nuevo cine latinoamericano!

\begin{abstract}
iGracias Fernando!
Cuando terminé, envié el DVD del documental a Fernando. Me escribió un comentario que agradezco. Porque este maestro, gran pedagogo, que al dejarse filmar tanto me enseńó lo que era filmar, completó el retrato que yo intenté hacer lo mejor posible. Con increíble humildad me agradeció no por el DVD, sino por el documental...
\end{abstract}

